\title{
SIMULATION FOR MANAGEMENT AND ORGANIZATION OF CONSTRUCTION MACHINERY
}

\author{
Yoshikazu SASAKI, Eiji MURO \\ Technical Research Laboratory. Takenaka Corporation \\ 2-5-14 Minamisuna, Koto-ku, Tokyo 136, Japan \\ Osamu FURUKAWA, Shuzo FURUSAKA, Kazuyoshi ENDOH \\ Department of Architecture, Faculty of Engineering, Kyoto University \\ Yoshida-Honmachi, Sakyo-ku, Kyoto 606, Japan
}

\begin{abstract}
The development of machinery becomes successful only with their popular use which is greatly influenced by the rate of operation. This requires workable policy decisions which address the possession and allocation of machines in conformity with various project environments and the nature of the machines. This paper dealt with the operation rate by using computer simulation, on the assumption of changing construction work volume range of allocation and internal possession of machines. Set forth here are the metric bases for considering the possession and allocation of machines.
\end{abstract}

\section{Introduction}

Most construction machines cannot be consumed in one project alone. This is why machinery owners need to maintain their operation rate at as high a level as possible by assigning them to the next project without keeping them idle after one project. On the other hand, the organizers of individual construction projects require an environment where machines can be easily allotted to their work sites. The ownership and assignment of machines are also affected by the policies of related businesses as well as the market environment. Little is known about those interdependent relations.

In recent years there have been energetic drives to develop new types of machines, including construction robots. In order to make closely link their technologies to the realities, it is important to reasonably determine who owns the machines and who assigns them to individual projects, and for what terms. The objective of this paper is to identify the interrelationships between the allotment environment and the operation rates of the machines in various cases by computer simulation, and is to clarify the foundations of a new policy of machine operations.

\section{Possession of Machines and Their Assignment Environment}

\subsection{Market Environment}

The work load to which construction machines are allocated greatly differs with the region, such as urban or local areas. This work load is far from fixed. To be more specific, work volume increases or decreases as the economy grows or declines, and shows cyclic fluctuations with changes in the economic situation and seasons. These concern the overall construction work volume in a certain area, an indication that there may be much greater fluctuations in work load individual entities are assigned. 


\section{Owners}

It is difficult to give a precise account of the ownership of construction machines in Japan. This is mainly because how many machines owned are scrapped and how many second-hand ones are traded are not known. To speak roughly on the basis of our own studies, construction machines are held by general contractors, sub-contractors and rental firms. Their ratios of holdings are fluid and vary depending on the natures of machines.

General contractors have owned machines by developing or purchasing them by themselves, if they are essential for their contracts, but are not to be supplied by outside entities. Among others, major general contractors have been able to keep owning the machines thanks to an enormous amounts of contracts. They hold a great majority of heavy-duty cranes, cubicles (temporary compartment for receiving power), and so on.

Some sub-contractors, while owning machines for themselves, have expanded their work scope by obtaining orders from general contractors, involving both machines and labor services. In these cases, they are normally paid for machine operations and labor services at a piece-work rate, which is quite different from a time rate. Relatively many machines for piling and excavating are held by them.

The rental business is quite new. Its fleets of machines are growing partly because they are leased to a wide range of construction firms. Most of them are popular multi-purpose machines.

\section{Organizers of Construction Works}

There is no fixed organization of "sub-package" for building construction. The term "sub-package" is used because it counts for much to decide not only the internal package of each resource, such as manpower, machines and materials, but also the scopes of assignment by combining them. This operation can be classified into two opposite types, one being to reduce the scope -- to achieve higher efficiency by specializing in a limited area of work -- and the other to expand them -- to offer an incentive to the implementation of jobs, to expand the scale of sub-contractors and upgrade its potential capacity. Given the characteristic individuality of each building project and the diversity of resources, we are of the opinion that it is more favorable for both organizers and sub-contractors to manipulate this range.

The rule in Japan is for a general contractor to take a lump-sum contract of a given construction project and play the role of coordinating the whole of the construction work. Therefore a general contractor is a primary organizer and sub-contractors secondary organizers in their work scope.

\section{4 Relationships between Organizer and Machine Owners}

There are two cases: in one case a general contractor allocates machines and in the other sub-contractors are responsible for the allocation of machines and manpower. In the two cases they sometimes use their own machines and sometimes procure them from outside businesses. In other words, a construction organizer is also an owner of machines, while there are outside owners. In allocating machines to individual work sites, priority normally goes to those held internally, and outside machines are brought in to make up for the shortage.

Needless to say, the deployment of machines is influenced by the policy both of the organizer and their owners. The organizer finds it impossible to mobilize for the given contract all the available machines. By the way, there are times when any owner other than the general contractor concerned forms capital affiliations or enduring working relations with the general contractor. In short there often exist intermediary entities between the inside and outside of company.

What attracts a particular notice is a practice called "accommodation" which 
substantially enlarges the potential range of allocation. This practice is the lease of machines to another owner only while they are idle without forming direct contractual relations with the organizer. This quantitative ratio has an inherent limit, and if it goes up too high, the machines thus leased cannot be called internal any longer.

\section{Simulation Model}

A strategic value appraisal method can be adopted for the allocation of construction machines to individual projects, which weighs the possibility of taking orders and their profits. This approach may work when the construction organizer and the machine owners are separate entities and can choose each other freely. However, this method is flawed by the following two problems:

In the first place, there are different cost mechanisms with internal and external resources allowed to exist side by side. Internal resources must be maintained even while they are left idle. However, a high rate of operation can make internal resources an excellent method of ownership and allocation superior to that of external resources, whose price is determined by taking the risks of idleness into account.

The second is whether or not there are always idle resources which are available for assignment. Assume that there are and it implies that the fraction expressing the operation rate (as calculated by the number of machines deployed / the total number) has an excessively large denominator. As a matter of fact, it is possible that the owner cannot afford to keep the machines if the operation rate remains all that low.

This paper attempts to measure the operation rates of machines by simulating various environments. The processes adopted are illustrated in Fig. 1.

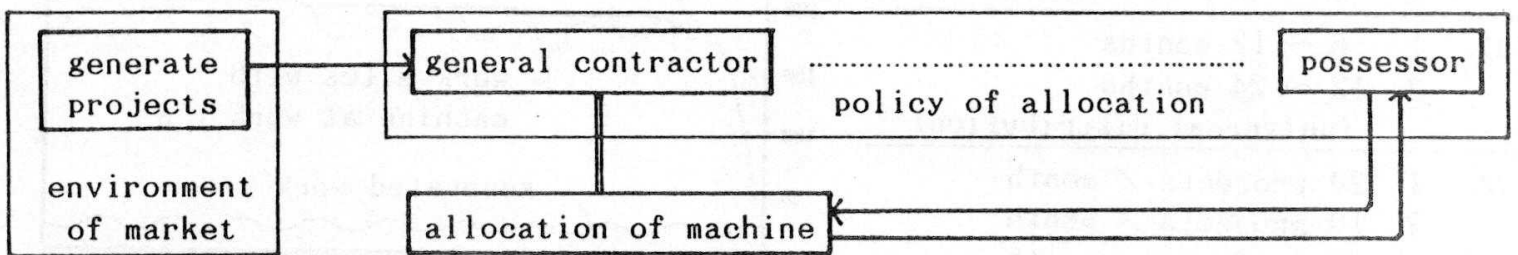

Fig. 1 Simulation process

(1) Generate a project in the target area. Here the SIN curve of a yearly cycle with one month as a unit is employed. The construction duration is regarded as the property of machines. Their long binding term alleviates fluctuations in the number of work sites where machines are in action.

(2) A general contractor is selected by a random number to be awarded a project. Here each general contractor is given a particular probability of winning the contract in question.

(3) Assume the same number of machine owners as general contractors. Any general contractor with its own machines is counted in as a separate owner.

(4) The machines held by each owner are allocated to individual works of each general contractor in accordance with the policy set forth for each task. This policy concerns the range of allocation, the order of priority and those who buy machines in the case of shortage.

Once assigned to a given work site, they are not to be replaced during the period, and are to be returned to their owner after use. Set ownership at nothing at each firm at the outset of the simulation, and an assessment is to be made after a certain period that the number of machines held stabilizes.

Factors excluded here may be the following:

The first is a delay in the commencement of work for which the machine is being 
reserved. For instance more often than not machines are not allocated to the work site because of neighborhood issues. The machines remain idle during this period.

The maintenance period is a second factor. Machines undergo maintenance servicing for a fixed period before or after allocation to a given work site but this consideration is omitted to make computed results common. Also excluded are the scrapping of outdated or worn machines.

A third factor disregarded is the presence of different maintenance costs among owners and price-determining policy. Here all the costs are assumed to be identical for the sake of convenience.

\section{Conditions Set and the Number of Construction Sites With Machines at Work}

Three kinds of work load variations, two kinds of construction durations and three types of occurrence rates are set, as illustrated in Tab. 1 . Machine allotments are simulated below under the environments combining those values. Each of those environments is referred to "Case-NNN".

Fig. 2 traces the amount of construction work generated in one case, trends in the number of work sites with machines in action, and the definition of their operation rate used here. The change in the overall number of work sites is determined by the set condition where projects are generated. The number of work sites of each individual firm fluctuates more largely, which is because the contract-winning chance of each firm is set as a probability.

Tab. 1 Assumption

\begin{tabular}{llc}
\hline $\mathrm{V}$ & 1 & constant \\
& 2 & $\mathrm{M}+\mathrm{M} / 4 \times \sin \mathrm{t}$ \\
& 3 & $\mathrm{M}+\mathrm{M} / 2 \times \sin \mathrm{t}$ \\
\hline $\mathrm{D}$ & 1 & $6 \sim 12$ months \\
& 2 & $12 \sim 24$ months \\
& & (universal distribution) \\
\hline $\mathrm{M}$ & 1 & 20 projects / month \\
& 2 & 10 projects / month \\
& 3 & 5 projects / month
\end{tabular}

probability of winning chances

each 10 general contractor : 10\%

Where $\mathrm{V}$ : work load variation

D : duration

M : average of generation

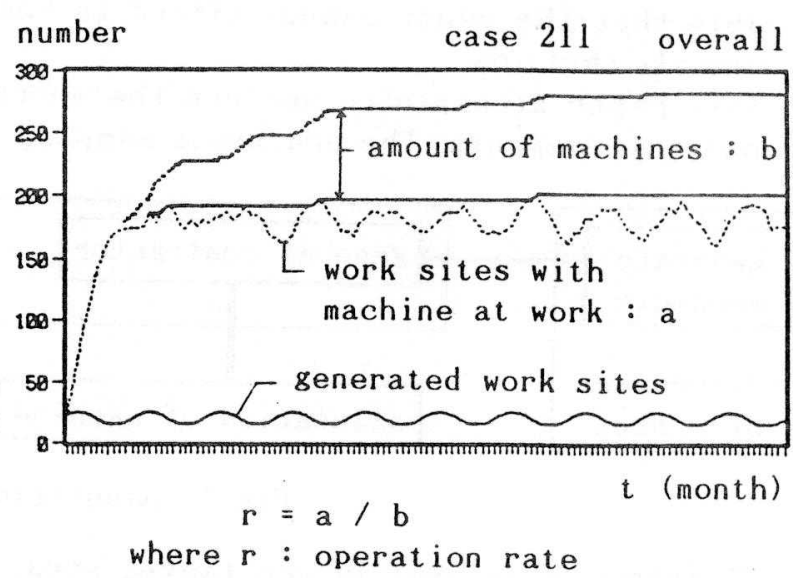

Fig. 2 Condition of the number of construction sites

As the load of construction work fluctuates and the construction duration is spread within a certain range the number of construction sites changes. Since the quantities of machines held does not change so rapidly, their operation rate varies in time series. Subsequently in this model, the maintenance of a high operation rate is a matter of keeping down the gross quantity of machines vis-a-vis the volume of construction work. Hereinafter, the average operation rate alone is often shown, for the sake of providing an easy understanding of simulation results, but attention should be paid to differences in the unevenness of operation rates among individual firms and the overall ones.

\section{Range of Allocation}

Fig. 3 models the operation policy assumed. In the case of allocating machines to one firm alone machines are assigned between the entities with an identical number, and their owners immediately procure the machines needed if all of their 


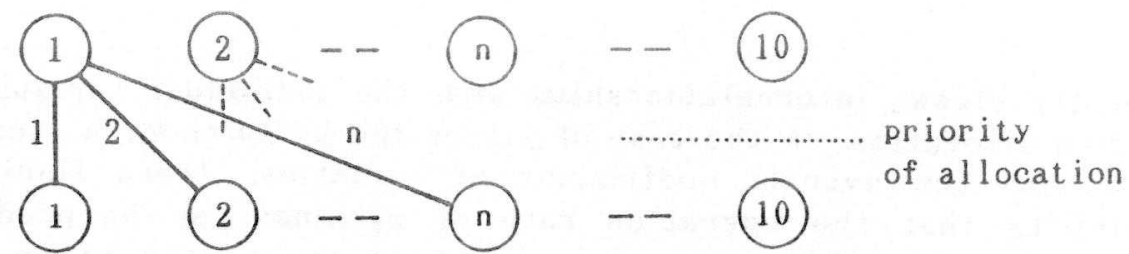

Fig. 3 Modelled policy in various range of operation

machines are at work. In the case of two firms, allocation is first discussed among the companies concerned, and the diversion of machines at the disposal of a second owner is considered to meet any shortage. If the diversion is not sufficient, the machine owner first mentioned increases his fleet of machines. Likewise, the policy is set for allocation to up to ten firms. In the last case of ten-firm allocation, the overall number of machines will not be increased if only one machine is idle anywhere. If the range of allocation is limited, there may be one owner whose machines are all operating at full capacity, while some have their's idle. This situation is alien to the ten-firm allocation scenario where the overall operation rate is in the ideal state, which is, however, quite unlikely in reality. Considering that the organizer is concurrently an owner of machines, hereinafter, the number of machines allocated to the firms with the identical number is represented as the internal operation rate.

Fig. 4 illustrates the allocation range and the distribution of operation rates in one case. The expansion of the allocation range does much to raise the overall operation rate. There should be a time under whatever conditions when the operation rate reaches $100 \%$ on an individual base, since new purchases are made only to satisfy a shortage. However, the distribution of operation rates changes greatly, depending on the load of construction work and the allocation policy. The distribution ranges extensively on the individual base and converges in a definite range on the overall base, which shows that individual firms do not have the same operation rate at any identical point.

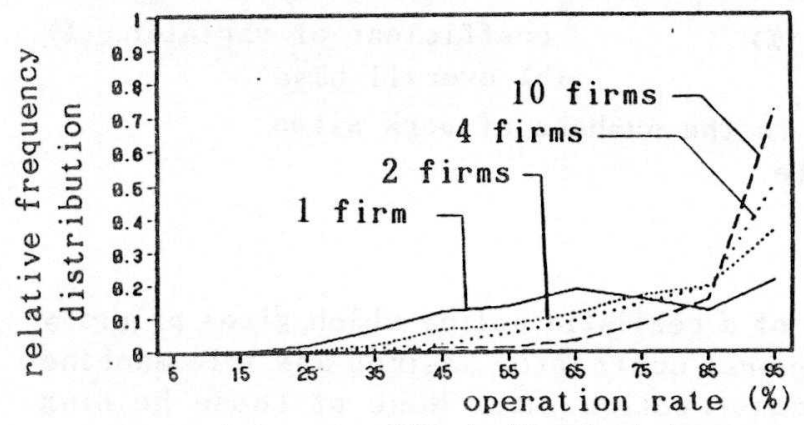

(a) case 123 individual base

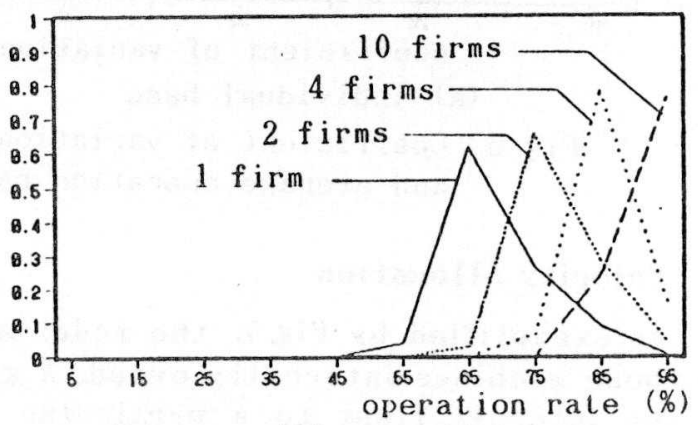

(b) case 123 overall base

Fig. 4 Distribution of operation rate in various allocation range

Fig. 5 describes the relations observed between the allocation scope and the operation rate in two cases, one showing the highest operation rate and the other the lowest figure. The expansion of the range of allocation has a great effect of improving the operation rate while it is in its early stage. In this early stage of expansion, a three-firm allocation is achieved over half of the improvement in the operation rate from the one-firm scenario to the ideal state achieved in this phase. As the allocation range expands, the internal operation rate drops at a rate, which can be managed in the scenario involving about three firms.

Fig. 6 discusses the interrelationships between the coefficient of variation in the number of work sites with machines in operation and the average operation rate in individual and overall cases. It is obvious that the operation rate of machines has much to do with the variation of the number of work sites; there are 
naturally closer interrelationships with the individual variation coefficient in one-firm allocation. In the case of allocation by $10 \mathrm{firms}$ a closer association is found with the overall coefficient of variation. These findings indicate the possibility that the operation rate of machines can be predicted, given the coefficient of variation in the number of work sites where machines are in operation.

$\square \quad 1 \mathrm{firm}$ allocation $+3$ $\diamond 10$

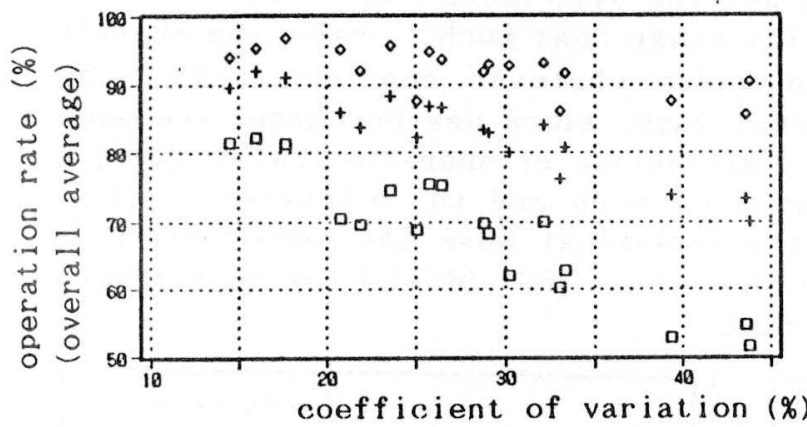

(a) individual base

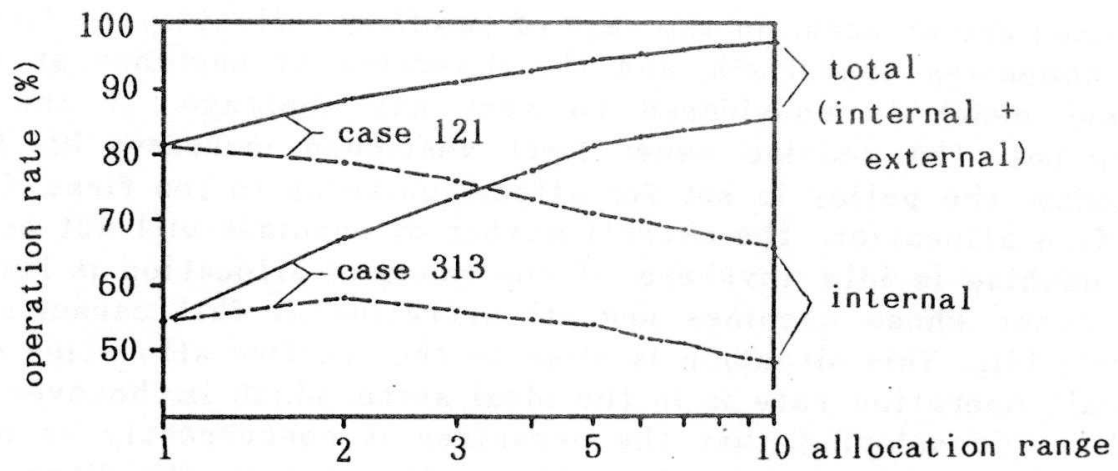

Fig. 5 Relations between allocation range and operation rate

Fig. 6 Coefficient of variation in the numbers of work sites and average operation rate

\section{Priority Allocation}

As exemplified by Fig. 7, the model is of a realistic policy which gives priority to those machines internally owned. A general contractor assigns any idle machine in the internal fleet to a particular construction site. None of those holding their own fleets diverts machines to the works of any other general contractor. There are outside fleets to which general contractors can get access. When neither the general contractor nor the outside owner approached has any idle machine, the latter gets a new one. It is possible to calculate the expected values as regards the number of construction sites with machines are in operation, in this simulation from the assumed conditions for project occurrence. This section is devoted to the measurement of different operation rates by changing the ratio of the number of machines held internally to all of the expected values.

The results are given in Fig. 8. The operation rate of internally held machines given priority rises while their ratio to the whole remains low, and falls as the figure grows. On the other hand, the figure for handicapped outside machines goes down with every increase in the ratio of priority assignments. The extent of such a fall differs according to the number of machine-operating work sites. The overall operation rate can be sought by obtaining the weighted mean of machines held inside and outside the company. The rate does not change at all as long as the priority assignment ratio stays within about $50 \%$. 


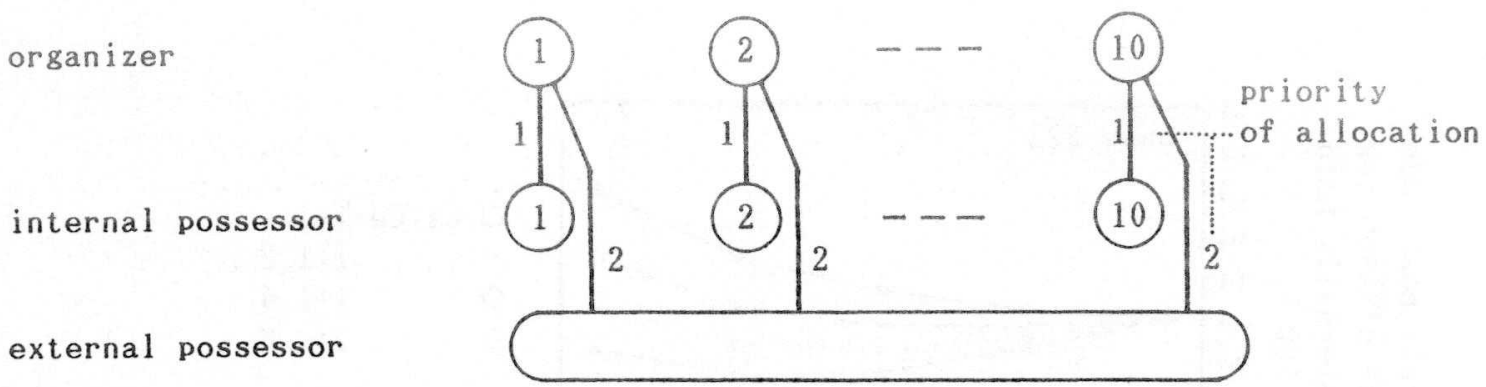

Fig. 7 Modelled policy in priority allocation

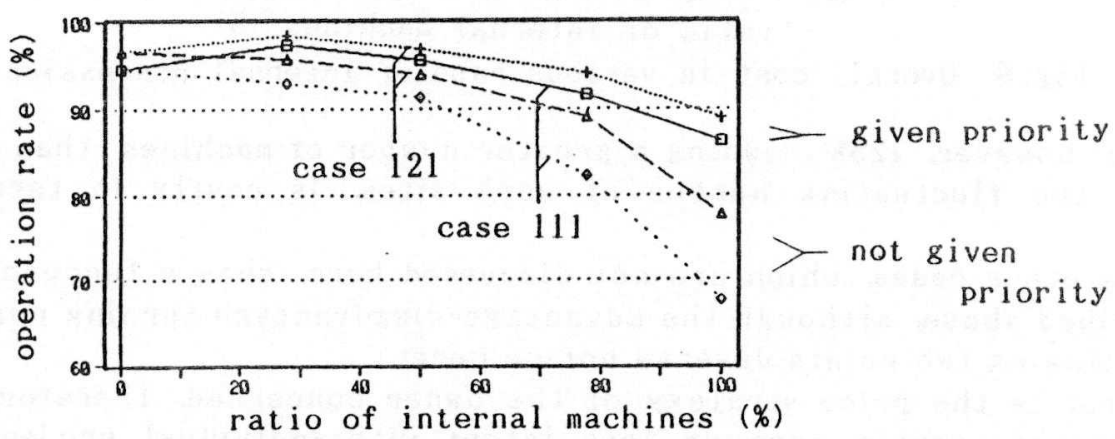

Fig. 8 0peration rate in priority allocation

These findings indicate the possibility of cutting the cost and moreover the possibility that more expensive machines can be possessed while retaining the competitive edge. New types of machines tend generally to be expensive in terms of maintenance costs inclusive of breakdowns when their operation begins and they are improved. Apply these findings to the case of internally owning the machines, which are developed independently and are at the important juncture of their popularization, and you can realize the effectiveness of the policy of giving priority to internal machines while keeping the number of owned ones at a certain level.

\section{Ratio of Internal 0wnership}

The contents of time rate ought to be examined in order to incorporate the above results in the next-stage of the operation policy. The organizer is preoccupied with the unit price of the time rate which covers the operation period alone and there is no need at all to pay for the idle period of outside machines. Therefore, this unit price, $C_{e}$ is normally set by adding the expenses for the idle period to those for the operation period. On the other hand in the case of internal machines, it is a more realistic supposition that the cost of owning and maintaining machines is constant whether or not they are in operation. Assume this unit cost is $\mathrm{Ci}_{\mathrm{i}}$ and set the operation rate at $r$ (0-1). In simplified terms they have the relation shown below.

$$
\mathrm{Ci} \times 1 / \mathrm{r}=\mathrm{Ce}
$$

Where $\mathrm{Ce}$ is higher. Computed here are the overall costs with $\mathrm{Ci}$ set as 1 and $\mathrm{Ce}$ multiplied from 1 to 1.6. The results are shown on Fig. 9.

With $\mathrm{Ci}: \mathrm{Ce}=1: 1$, it is naturally more advantageous to use outside machines simply because there is no expense needed for idleness. If there is a cost difference, the internal possession of a certain quantity turns out to be more profitable. In the case discussed in the figure, if the ratio is 1.2 times, the internal possession of about $50 \%$ is more favorable. If the figure is 1.4 times, about $75 \%$ pays. If the difference is as much as 1.6 times, $100 \%$ possession is to the advantage. It is hard to tell what extent of cost difference is a realistic 


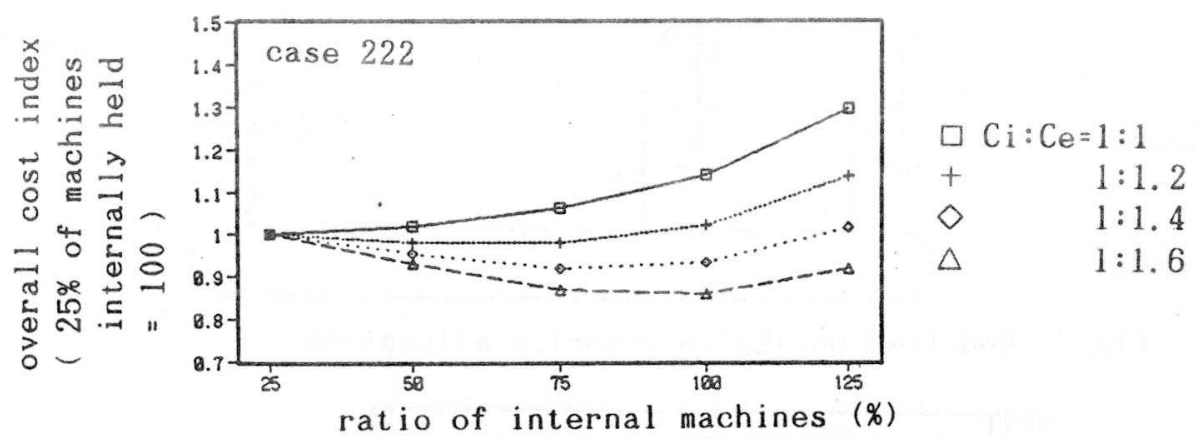

Fig. 9 0verall cost in various rate of internal possession

assumption, however, 125\%, owning a greater number of machines than the average value for the fluctuating number of work sites, is costly in terms of total expenses.

All the other cases, which are not discussed here, show a tendency similar to that described above, although the advantage-disadvantage turning point changes.

The following two points deserve notice here:

The first is the price strategy of the owner concerned. Therefore, probably cost differences remain more or less latent with individual projects, but the above principle works well with the average value.

The second is the continued availability of non-priority resources. This model suggests that the higher ratio of priority allocation makes the presence of outside machines look more unrealistic.

\section{Conclusion}

The development of machinery does not succeed without the policy for its popularization, for which, however, there has been little metrical bases. This paper dealt with the possession and allocation of machines by computer simulation, which represented the realistic environment of the management and organization of construction machinery.

All of the owners of construction machines do not have opportunities of having them allocated to all construction sites. Here we measured the effect of the expansion for allocation range for raising the operation rate. It is possible to improve the operation rate to a practical extent within certain limits.

Next we metrically considered the òperation status of machines which were worked under differing environments. The internal resources can attain a higher operation rate by restricting their amount to a certain level and pursuing a priority allocation policy. Herein lies the realistic aspect of internal ownership.

The results will be useful for the practical determination, whether the newly developed machines should be possessed internally or should be hired from external owners of them.

This model have the possibility of expansion to all resources for building construction, which will be the future development.

\section{References}

SASAKI, Y. et al. , "Decision Making Model of Roll and Resource Allocation -- Studies on Organization of Sub-package for Building Construction (2)", 3th "Kenchikuseisan to Kanri-gijutu" Symposium, 1987. Architectural Institute of Japan (AIJ)

SASAKI, Y. et al. , "Decision Making Model of Resource Allocation under Fluctuation in Construction Works -- Studies on Organization of Sub-package for Building Construction (3)", 4th "Kenchiku-seisan to Kanri-gijutu" Symposium, 1988, AIJ 